\title{
Knowledge, attitude and practice towards cervical cancer among women in Finote Selam city administration, West Gojjam Zone, Amhara Region, North West Ethiopia, 2017
}

\author{
Ayele Semachew Kasa*, Tadesse Dagget Tesfaye*, Worku Animaw Temesgen*,
}

Department of Nursing, College of Medicine \& Health Sciences, Bahir Dar University, Bahir Dar, Ethiopia.

*All authors contributed equally to this work.

\section{Email addresses:}

ASK: finoteayu24@gmail.com or ayele.semachew@yahoo.com

TDT: tadesse.dagget@yahoo.com

WAT: workimaw@gmail.com

\begin{abstract}
Introduction: Cancer of the cervix is the leading cause of cancer-related death among women, especially in developing countries affecting women at a time of life when they are critical to social and economic stability.

Method: The study was conducted at Finote Selam City Administration from February 01 to March 01, 2017 using a community-based cross-sectional study design. The representative sample size was selected using multistage sampling technique. The data were collected using an interviewer-administered questionnaire adapted from the previous study. Data were entered using EpiData Version 3.1 statistical software and analyzed using SPSS version 20 statistical package.

Result: One hundred seventy (23.1\%) were knowledgeable about cervical cancer whereas 63\% of participants had a negative attitude and only $7.3 \%$ had ever screened for the disease. Logistic regression analysis showed that age, marital status, religion, experienced sexual intercourse and age at $1^{\text {st }}$ sexual intercourse were found to be significantly associated with the knowledge of cancer of the cervix.

Conclusion: Ministry of health in collaboration with other concerned bodies should design a strategy to give education about cervical cancer including information on risk factors, signs and symptoms; and availability of screening should be provided for women and as well as for the public.
\end{abstract}

Keywords: Cervical cancer, screening, Finote Selam, North West Ethiopia.

DOI: https://dx.doi.org/10.4314/ahs.v18i3.20

Cite as: Kasa AS, Tesfaye TD, Temesgen WA. Knowledge, attitude and practice towards cervical cancer among women in FinoteSelam city administration, West Gojjam Zone, Ambara Region, North West Ethiopia, 2017. Afri Health Sci. 2018;18(3): 623-636. https:/ / dx.doi.org/ 10.4314/ abs.v18i3.20

\section{Corresponding author: \\ Ayele Semachew Kasa, \\ Department of Nursing, College of Medicine \& Health Sciences, \\ Bahir Dar University, Bahir Dar, Ethiopia. \\ Email: finoteayu24@gmail.com, ayele.semachew@yahoo.com}

\section{Introduction}

Cancers that originate in the female reproductive system are called women's reproductive cancers. These include cancer of the cervix, breast, ovaries, vagina, vulva, and endometrium ${ }^{1}$. Cervical cancer is an important women's reproductive health problem, especially in developing countries. Cervical cancer, though largely preventable, is the second most common female cancer internationally and a leading cause of cancer deaths among females in

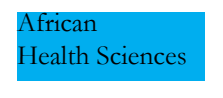

C) 2018 Kasa et al. Licensee African Health Sciences. This is an Open Access article distributed under the terms of the Creative commons Attribution License (https://creativecommons.org/licenses/BY/4.0), which permits unrestricted use, distribution, and reproduction in any medium, provided the original work is properly cited. 
the developing countries ${ }^{2}$. Human papilloma virus, a common sexually-transmitted infection, is the primary underlying cause of cervical cancer. Multiple sexual partners, early age of onset of sexual activity, increasing parity, early age of marriage and child birth, poor personal hygiene, low socio-economic status, use of hormonal contraceptives for 5 years or longer, current or previous sexually-transmitted infection and smoking are the risk factors for cervical cancer ${ }^{3,4}$.

Cancer of the cervix is the leading cause of cancer-related death among women, especially in developing countries affecting women at a time of life when they are critical to social and economic stability ${ }^{5}$. Of $86 \%$ of all cervical cancer diagnosed, $88 \%$ of death occur in developing regions of the world ${ }^{3}$. Every year, 500000 new cases are diagnosed and 270000 women die of this disease, mostly $85 \%$ in developing countries ${ }^{6}$.

Cervical cancer is increasingly recognized as a critical public health problem in Africa. While communicable diseases continue to burden African populations. Increases in life expectancy, changes in diet and lifestyle, and lower burden of communicable diseases promise to increase the cancer burden in Africa over the coming years ${ }^{7}$.

A majority of cancers including cervical cancer are diagnosed at an advanced stage of disease because of lack of screening and early detection services, as well as limited awareness of early signs and symptoms of cancer ${ }^{7}$. Cervical cancer awareness is generally low worldwide but worse in developing countries despite the increased prevalence of the disease in these countries ${ }^{8}$.

Most patients and their families don't properly know what a cancer is and its treatment options. Consequently, $80 \%$ to $90 \%$ of cancer patients already suffer from advanced and incurable cancers at the time of diagnosis. The families also do not have adequate knowledge of home-based care to be given for the patients and consequently they fail to provide such care to their patients?

Cervical cancer prevention efforts worldwide have focused on screening women at risk of disease using pap smears and treating pre-cancerous lesions. Cytology-based screening (Pap smear test) is considered the best approach to reduce cervical cancer incidence in developing countries ${ }^{2,10,11}$.

Ethiopia has invested little in the infrastructure, training, and laboratory capacity required for successful Pap smear screening $^{10}$. In resource-limited countries like Ethiopia, cervical cancer prevention will be successful and cost-effective because it requires few visits and we offer a "screen and treat" (single-visit) approach ${ }^{12}$.

Nevertheless, the level of women's awareness about cervical cancer is unknown. Knowledge, attitude, and practice (KAP) are important elements for designing and monitoring in awareness creation and screening programs.

The aim of this study was to assess Knowledge, Attitude, Practice and factors associated with uptake of cervical cancer screening among Finote Selam City Administration Community, West Gojjam Zone, Amhara Region, North West Ethiopia, 2016.

\section{Methods and materials}

The study was conducted at Finote Selam City Administration using Community-based cross-sectional study design. The study was conducted from February 01 to March 01, 2017. Finote Selam is a relatively young city, which was founded in 1947. Its foundation and naming in one way or another, was the result of the resistance against the Italian occupation of the country. Finote Selam is situated in the Amhara National Regional state at 376 k.m away from Addis Ababa city towards NorthWest direction of the country, geographically located at latitude $10^{\circ} 41^{\prime} 23^{\prime \prime}$ North of the Equator and longitude $37^{\circ} 15^{\prime} 35^{\prime \prime}$ East of the Prime Meridian. The city administration has three urban and two rural (Bakel and Shembekuma) kebeles with a total area of 1663.14 hectares. The population aged between 15-64 years and those above 64 years is $68 \%$ and $2.25 \%$, respectively.

The study population of the study was those women whose age is 15 years and above residing in Finote selam City Administration.

\section{Sample size and sampling procedure}

Sample size was calculated using a formula for single proportion with the assumption of knowledge about cervical cancer screening $19 \%{ }^{13}$ with $95 \%$ confidence interval, margin of error taken as 0.04 . Then the sample size was 370, after adding 10\% none respondent rate and multiplying with a design effect of 2 , it became 814 . The representative sample size was selected using multistage sampling technique. The first household was taken by lottery method and if more than one eligible individual was present in the same household, one was recruited using lottery method, but if an eligible individual was not pres- 
ent in the selected household the next house was considered. The data were collected using an interviewer-administered questionnaire adapted from a previous study ${ }^{14}$.

\section{Data collection instrument}

Socio-demographic characteristics of the respondents which included age, educational level, and other relevant characteristics was developed by the investigator. The rest of the questions related to risk exposure, knowledge, attitude and screening practice towards cervical cancer were adapted from different published literature.

\section{Operational definition}

Questions regarding knowledge of risk factors, symptoms, treatment options and prevention and early detection measures for cervical cancer were scored and pulled together and the median score was computed to determine the overall knowledge of respondents.

Knowledgeable: Respondents scored above the median score of knowledge assessing questions.

Not knowledgeable: Respondents scored below the median score of knowledge assessing questions.

Positive attitude: Those respondents who scored above median score of attitude assessing questions.

Negative attitude: Those respondents who scored below median score of attitude assessing questions.

Practice: Those respondents who screened for cervical cancer at least once ${ }^{15}$.

\section{Personnel for data collection and data quality control}

A total of six data collectors were recruited to distribute and collect the data and two supervisors supervised the overall data collection process. To ensure the quality of the data, the data collectors and supervisors trained for one day before the actual data collection regarding the approach, objective of the study, ethical issues including how to approach the respondents. The supervisor routinely did a checkup for the completeness and consistency of the data.

To check for the accuracy of responses, language clarity, and appropriateness of the tools; the questionnaire was pre-tested on $5 \%$ (41) of the total sample size before a week of the actual data collection period in Bahir Dar City Administration.

\section{Data processing and analysis procedures}

The collected data were edited, coded, categorized and entered into EpiData version 3.1 and exported to SPSS version 20.0 windows statistical software for analysis.

Variables with P-value $\leq 0.20$ in binary logistic regression analysis with 95\% confidence interval was used to assess the degree of association between dependent and independent variables. Variables which had a significant association with the outcome variable in the bivariate analysis were entered into the multivariable logistic regression analysis to form the model and variables having P-value of $<0.05$ were considered as statistical significance to determine the association.

Then the data were summarized using graphic presentations for the interpretation of findings and descriptive statistics based on percentages and frequencies.

\section{Ethical consideration}

Ethical clearance was obtained from Research Ethical Review Committee (RERC) of Bahir Dar University College of Medicine and Health Sciences. Permission and supporting letter were secured from Amhara National Regional State Health Bureau and Finote Selam City Administration Health Office before data collection. Verbal informed consent from each study participant was also obtained during data collection. The respondents had the right to refuse to take part in the study as well as to withdraw at any time during the study. No names or identifying information was indicated on the questionnaires, and all subjects were assured of confidentiality.

\section{Results \\ Socio-demographic characteristics of study partic- ipants}

From the total of 814 sampled study participants, 735 were successfully interviewed yielding a response rate of $90.3 \%$. The age distribution of the respondents showed that $274(37.3 \%)$ were between 24-34 years of age. The mean age of participants was $30.8 \pm 9.8 \mathrm{SD}$ years, with a minimum of 17 and maximum of 88 years. From all study participants, 633 (86.1\%) were Christian Orthodox religion followers, $344(46.8 \%)$ were single in their marital status, $111(15.1 \%)$ and $248(33.7 \%)$ were illiterate or had a diploma in their educational status respectively, and 263 $(35.8 \%)$ were merchants in their occupation. Four hundred one $(54.6 \%)$ of the total respondents had a child/ children and of these, $308(41.9 \%)$ had 1 to 3 children (Table 1). 
Table 1: Socio-demographic characteristics of study participants, Finoteselam City Administration (n=735) Amhara Region, Northwest Ethiopia, 2017.

\begin{tabular}{llcc}
\hline Socio-demographic characteristics of the respondents & N & \% \\
\hline \multirow{4}{*}{ Age category } & $<24$ years & 231 & 31.4 \\
& $24-34$ years & 274 & 37.3 \\
& $35-49$ years & 193 & 26.3 \\
\hline Religion & $>49$ years & 37 & 5.0 \\
& Orthodox & 633 & 86.1 \\
& Muslim & 71 & 9.7 \\
\hline Marital Status & Protestant & 31 & 4.2 \\
& Married & 290 & 39.5 \\
& Single & 344 & 46.8 \\
& Other* & 101 & 13.7 \\
\hline \multirow{3}{*}{ Educational Status } & Illiterate & 111 & 15.1 \\
& Primary school completed & 126 & 17.1 \\
& Secondary school completed & 82 & 11.2 \\
& College/university student & 111 & 15.1 \\
& Diploma & 248 & 41.9 \\
& 4 to 6 & 75 & 10.2 \\
& More than 6 & 18 & 2.4 \\
\hline Total & & 735 & 100 \\
\hline
\end{tabular}

Other* ${ }^{*}$ Widowed, divorced

\section{Risk exposure status among study participants}

Among all interviewed 735 study participants 431 (58.6\%) had experienced sexual intercourse. The mean age of experiencing the first sexual intercourse was $19.18 \pm 3.08$ SD years old, with a minimum of 10 and maximum of 32 years of age. Of these; 101 (23.4\%) experienced sexual intercourse below the age of 18 . Three hundred three
$(41.2 \%)$ of the total respondents had ever used modern contraceptive methods. Of these, 84 (11.4\%) used oral contraceptive (OCP), 173 (23.5\%) injectable and 37 $(5.0 \%)$ Norplant. The mean age of modern contraceptive methods utilization among study participants was $2.78 \pm$ 1.97SD years with the minimum of 2 months and a maximum of being 9 years. Currently $81(11.0 \%)$ study participants were using OCP (Table 2). 
Table 2: Risk exposure status among study participants, Finoteselam City Administration (n=735) Amhara Region, Northwest Ethiopia, 2017.

\begin{tabular}{llll}
\hline Variables in the study & & $\mathbf{N}$ & $\mathbf{\%}$ \\
\hline Have you ever experienced & Yes & 431 & 58.6 \\
sexual intercourse? $(\mathrm{n}=735)$ & No & 304 & 41.4 \\
\hline Age at $1^{\text {st }}$ sexual intercourse $(\mathrm{n}=$ & $<18$ years old & 101 & 13.7 \\
$431)$ & $>=18$ years old & 330 & 63.6 \\
\hline Ever used contraceptive & Yes & 303 & 41.2 \\
$(\mathrm{n}=735)$ & No & 432 & 58.8 \\
\hline Type of contraceptive $(\mathrm{n}=303)$ & Oral contraceptive (OCP) & 84 & 11.4 \\
& Injectable & 173 & 23.5 \\
& Norplant & 37 & 5.0 \\
& Barrier method & 9 & 1.2 \\
\hline Length in utilizing & $<1$ year & 42 & 13.9 \\
contraceptives $(\mathrm{n}=303)$ & $1 \quad$ to 5 years & 210 & 69.3 \\
& $>5$ years & 51 & 16.8 \\
\hline Current user of OCP & Yes & 81 & 11.0 \\
& No & 654 & 89.0 \\
\hline
\end{tabular}

\section{Knowledge towards cervical cancer}

From all the study participants, 509 (69.3\%) had heard about cervical cancer. For $262(51.5 \%)$ respondents; their family and friends were the source of information, health workers were the source of information for 101 $(19.8 \%)$ respondents. Of those who had heard about cervical cancer, 221 (43.4\%) mentioned vaginal bleeding as a major symptom of the disease whereas, $292(57.4 \%)$ and
$322(63.3 \%)$ of them did not know the risk factors and the prevention strategies of cervical cancer respectively. Three hundred eighty-six $(75.8 \%)$ of study participants did not know that cervical cancer is curable in its earliest stage. Twenty-nine $(5.7 \%)$ of them know someone with the disease (Table 3).

Generally, from all study participants, 170 (23.1\%) were knowledgeable about cervical cancer (Figure 1). 
Table 3: Knowledge status of respondents towards cervical cancer, Finoteselam City Administration (n=735) Amhara Region, Northwest Ethiopia, 2017.

\begin{tabular}{|c|c|c|c|}
\hline Variables in the study & & $\mathbf{N}$ & $\%$ \\
\hline \multirow[t]{2}{*}{ Heard about cancer $(\mathrm{n}=735)$} & Yes & 612 & 83.3 \\
\hline & No & 123 & 16.7 \\
\hline \multirow{2}{*}{$\begin{array}{l}\text { Heard about cervical cancer }(\mathrm{n}=735) \\
\text { Source of information for cancer of the cervix }(\mathrm{n}=509)\end{array}$} & Yes & 509 & 69.3 \\
\hline & No & 226 & 30.7 \\
\hline \multirow[b]{2}{*}{ Source of information for cancer of the cervix $(\mathrm{n}=509)$} & Media & 84 & 16.5 \\
\hline & $\begin{array}{l}\text { Broachers, posters, printed } \\
\text { materials }\end{array}$ & 22 & 4.3 \\
\hline \multirow{6}{*}{ Symptoms of cervical cancer $(\mathrm{n}=509)$} & Health workers & 101 & 19.8 \\
\hline & Family \& friends & 262 & 51.5 \\
\hline & Others* & 40 & 7.9 \\
\hline & Vaginal bleeding & 221 & 43.4 \\
\hline & Faull smelling vaginal discharge & 201 & 39.5 \\
\hline & Do not know & 87 & 17.1 \\
\hline \multirow[t]{6}{*}{ Risk factors for cervical cancer $(\mathrm{n}=509)$} & Having multiple sexual partners & 89 & 17.5 \\
\hline & Early sexual intercourse & 84 & 16.5 \\
\hline & $\begin{array}{l}\text { Use of OCP for prolonged } \\
\text { period }\end{array}$ & 20 & 3.9 \\
\hline & Acquiring HPV & 13 & 2.6 \\
\hline & Cigarette Smoking & 11 & 2.2 \\
\hline & Do not know & 292 & 57.4 \\
\hline \multirow[t]{3}{*}{ Prevention from acquiring cervical cancer $(\mathrm{n}=509)$} & $\begin{array}{l}\text { Avoiding multiple sexual } \\
\text { intercourses }\end{array}$ & 82 & 16.1 \\
\hline & $\begin{array}{l}\text { Avoiding early sexual } \\
\text { intercourse }\end{array}$ & 70 & 13.7 \\
\hline & $\begin{array}{l}\text { Avoid prolonged OCP } \\
\text { utilization }\end{array}$ & 23 & 4.5 \\
\hline $\begin{array}{l}\text { Can cancer of cervix cured in the } \\
\text { earliest form }(n=509)\end{array}$ & $\begin{array}{l}\text { Through vaccination for HPV } \\
\text { Do not know }\end{array}$ & $\begin{array}{c}12 \\
322 \\
\end{array}$ & $\begin{array}{l}2.4 \\
63.3 \\
\end{array}$ \\
\hline \multirow[t]{4}{*}{$\begin{array}{l}\text { Treatment options for cervical cancer } \\
(\mathrm{n}=509)\end{array}$} & $\begin{array}{l}\text { Specific drugs are given by } \\
\text { hospitals }\end{array}$ & 285 & 56.0 \\
\hline & Surgery & 55 & 10.8 \\
\hline & Radiation therapy & 54 & 10.6 \\
\hline & Do not know & 115 & 22.6 \\
\hline \multirow{2}{*}{$\begin{array}{l}\text { Knowing the presence of screening methods for diagnosis } \\
(\mathrm{n}=509)\end{array}$} & Yes & 127 & 25.0 \\
\hline & No & 382 & 75.0 \\
\hline \multirow[t]{4}{*}{ How frequent is the screening $(\mathrm{n}=127)$} & Once every year & 81 & 63.8 \\
\hline & Once every three year & 4 & 3.1 \\
\hline & Once every five year & 3 & 2.4 \\
\hline & Do not know & 39 & 30.7 \\
\hline \multirow[t]{4}{*}{ Who should be screened $(\mathrm{n}=127)$} & All reproductive age women & 78 & 61.5 \\
\hline & Elderly women & 6 & 4.7 \\
\hline & Prostitutes & 5 & 3.9 \\
\hline & Do not know & 38 & 29.9 \\
\hline \multirow{2}{*}{$\begin{array}{l}\text { Do you know procedures used in the detection of cervical cancer } \\
(\mathrm{n}=127)\end{array}$} & Yes & 27 & 21.3 \\
\hline & No & 100 & 78.7 \\
\hline \multirow[t]{2}{*}{ Do you know anyone with cervical cancer $(\mathrm{n}=509)$} & Yes & 29 & 5.7 \\
\hline & No & 480 & 94.3 \\
\hline
\end{tabular}

* Others $=$ teachers, religious leaders 


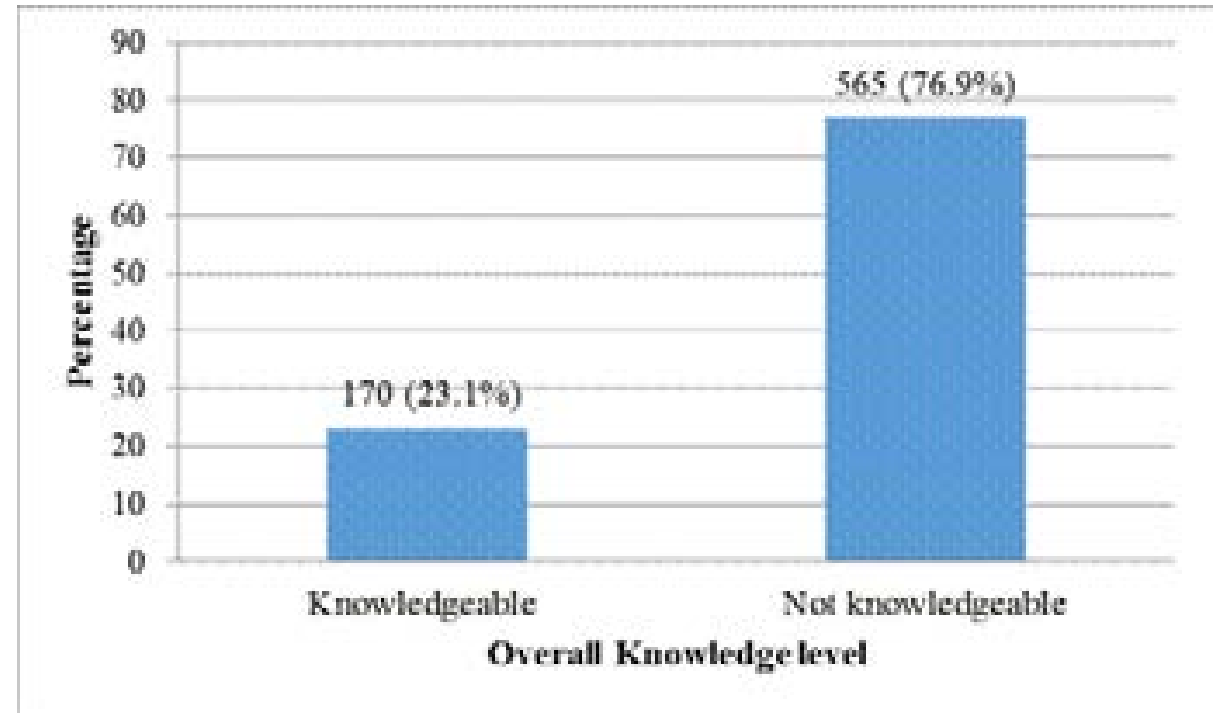

Figure 1: Overall knowledge status of respondents towards cervical cancer, Finoteselam City Administration $(n=735)$ Amhara Region, Northwest Ethiopia, 2017.

\section{Attitude towards cervical cancer}

From all study participants who heard about cervical cancer, $244(47.9 \%)$ have a positive attitude for the item "If screening is free and causes no harm, they will be screened." For the item "Screening for pre-malignant cervical lesions is not expensive"181 (35.6\%) had a positive attitude. Two hundred ten $(41.3 \%)$ of the study participants had a positive attitude towards the item "screening causes no harm to clients" whereas for the item "Any adult woman including you can acquire cervical carcinoma?", only $152(29.9 \%$ ) had a negative attitude (Figure 2). Generally, $272(37 \%)$ of study participants had a positive attitude towards cervical cancer screening (Figure 3). 


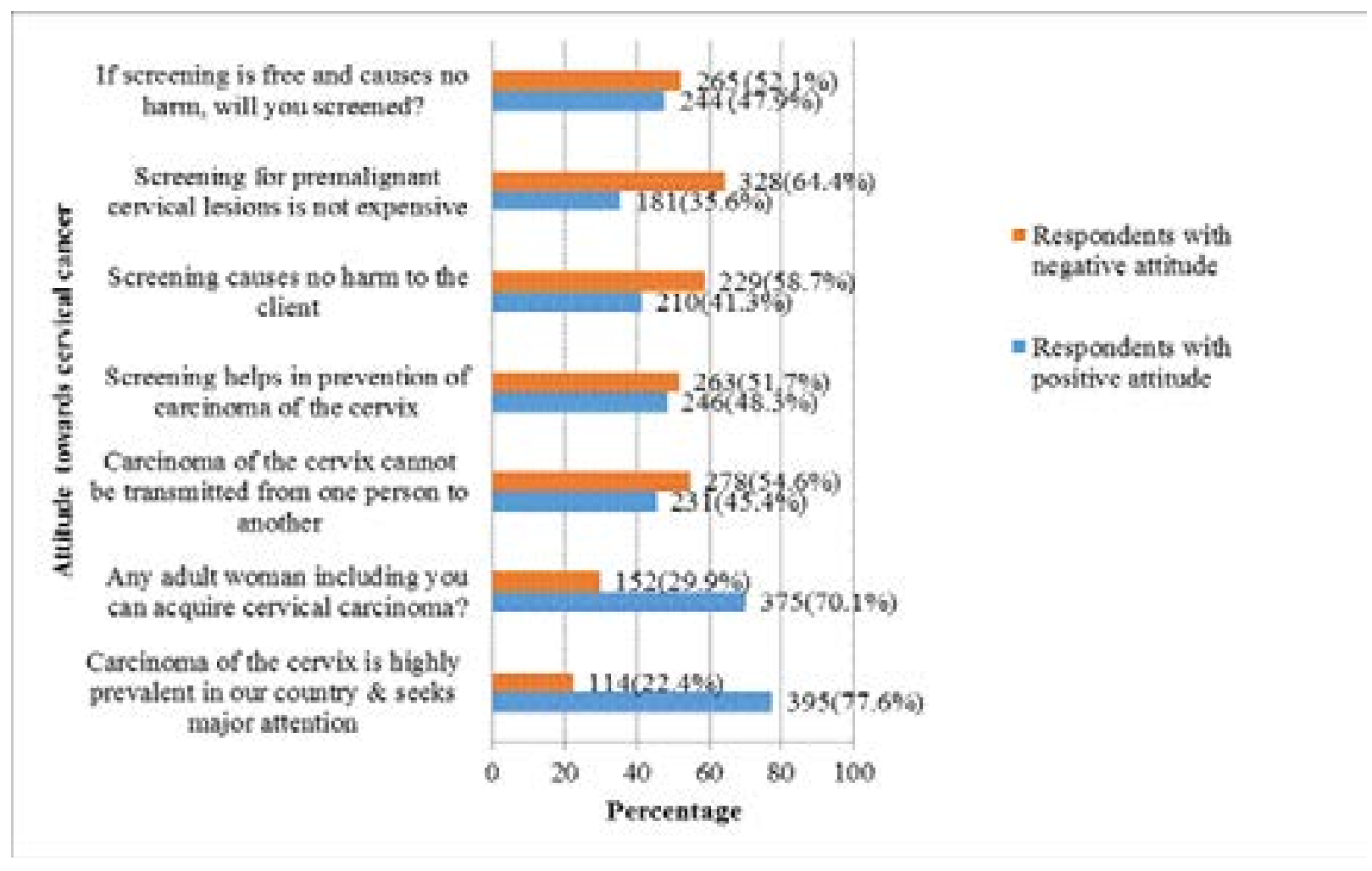

Figure 2: Attitude status of respondents towards cervical cancer, Finoteselam City Administration Amhara Region, North West Ethiopia, 2017.

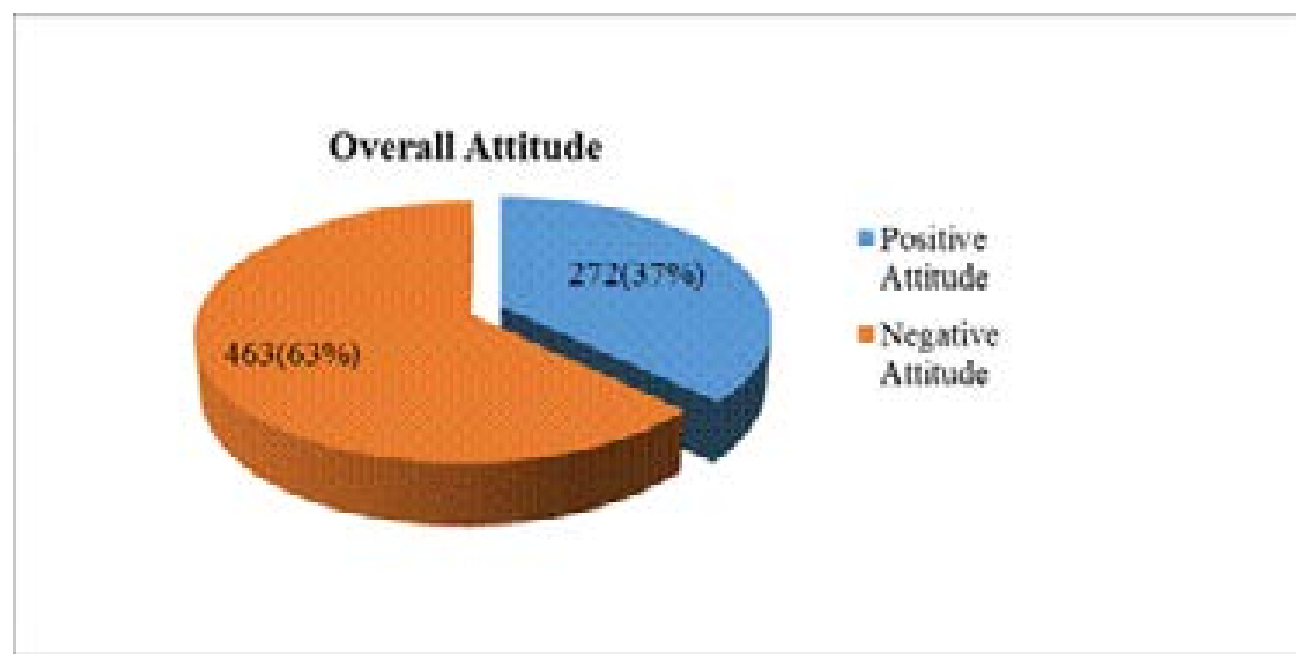

Figure 3: Overall attitude status of respondents towards cervical cancer, Finoteselam City Administration ( $\mathrm{n}=735)$ Amhara Region, Northwest Ethiopia, 2017.

\section{Screening practice for cervical cancer}

From all study participants, $142(19.3 \%)$ had heard about screening for cervical cancer and from these 54 (38\%) were screened for the disease. From those screened study participants, $45(83.3 \%)$ screened once in their lifetime.
Thirty-seven $(68.5 \%)$ of these initiated the screening by themselves and 34 (63\%) had been diagnosed before three years ago. Regarding for the reason for not screening, 334 (45.4) said it was because they felt they were healthy whereas $160(21.8 \%)$ it was because of fear of the result (Table 4). 
Table 4: Screening status for cervical cancer among study participants, Finoteselam City Administration (n=735) Amhara Region, Northwest Ethiopia, 2017.

\begin{tabular}{|l|l|c|c|}
\hline Variables in the study & $\mathbf{N}$ & $\mathbf{\%}$ \\
\hline \multirow{2}{*}{ Ever heard for screening $(\mathrm{n}=735)$} & Yes & 142 & 19.3 \\
\cline { 2 - 4 } & No & 593 & 80.7 \\
\hline \multirow{2}{*}{$\begin{array}{l}\text { Ever screened for any sexually } \\
\text { transmitted diseases }(\mathrm{n}=735)\end{array}$} & Yes & 397 & 54.0 \\
\cline { 2 - 4 } $\begin{array}{l}\text { Ever screened for cervical cancer } \\
(\mathrm{n}=142)\end{array}$ & No & 338 & 46.0 \\
\cline { 2 - 4 } & Yes & 54 & 38.0 \\
\hline \multirow{2}{*}{$\begin{array}{l}\text { How many times you screened }(\mathrm{n}= \\
54)\end{array}$} & Once & 88 & 62.0 \\
\cline { 2 - 4 } & More than once & 45 & 83.3 \\
\hline \multirow{2}{*}{$\begin{array}{l}\text { Who initiates you for screening }(\mathrm{n}= \\
54)\end{array}$} & Self-initiation & 37 & 16.7 \\
\cline { 2 - 4 } & Offered by health professionals & 17 & 68.5 \\
\hline \multirow{2}{*}{ Your last screening $(\mathrm{n}=54)$} & In the last three years & 20 & 31.5 \\
\cline { 2 - 4 } & More than three years ago & 34 & 63.0 \\
\hline \multirow{3}{*}{ Reason for not screening } & I am healthy & 334 & 45.4 \\
\cline { 2 - 4 } & I afraid the result & 160 & 21.8 \\
\cline { 2 - 4 } & I am not informed & 39 & 5.3 \\
\cline { 2 - 4 } & It may be painful & 148 & 20.1 \\
\hline
\end{tabular}

Factors associated with knowledge of cervical cancer

Candidate predictor variables from bivariate regression with knowledge of cervical cancer were entered to the multivariable logistic regression analysis. And the logistic regression analysis showed that age $(\mathrm{AOR}=2.8,95 \% \mathrm{CI}$ : 1.01, 7.9), marital status (AOR $=0.22,95 \% \mathrm{CI}: 0.06,0.70$ ), religion $(\mathrm{AOR}=8.8,95 \% \mathrm{CI}: 2.04,37.7)$, experienced sexual intercourse $(\mathrm{AOR}=2.9,95 \% \mathrm{CI}: 1.15,7.49)$ and age at $1^{\text {st }}$ sexual intercourse (AOR $=3.7,95 \%$ CI:1.8-7.5) were found to be significantly associated with the knowl- edge of cancer of the cervix. The odds of respondents in the age range of 35-49 years being knowledgeable about cervical cancer were 2.8 times more as compared to other age groups. Protestant religion followers were 8.8 times more likely to be knowledgeable than other religion followers. Those who had no history of sexual intercourse were almost 3 times more likely to be knowledgeable than those who had sexual intercourse and from those who had experienced sexual intercourse at the age $>=18$ years were 3.7 more likely to be knowledgeable than their counterparts (Table 5). 
Table 5: Factors associated with knowledge towards cervical cancer among study participants, Finoteselam City Administration (n=735) Amhara Region, Northwest Ethiopia, 2017.

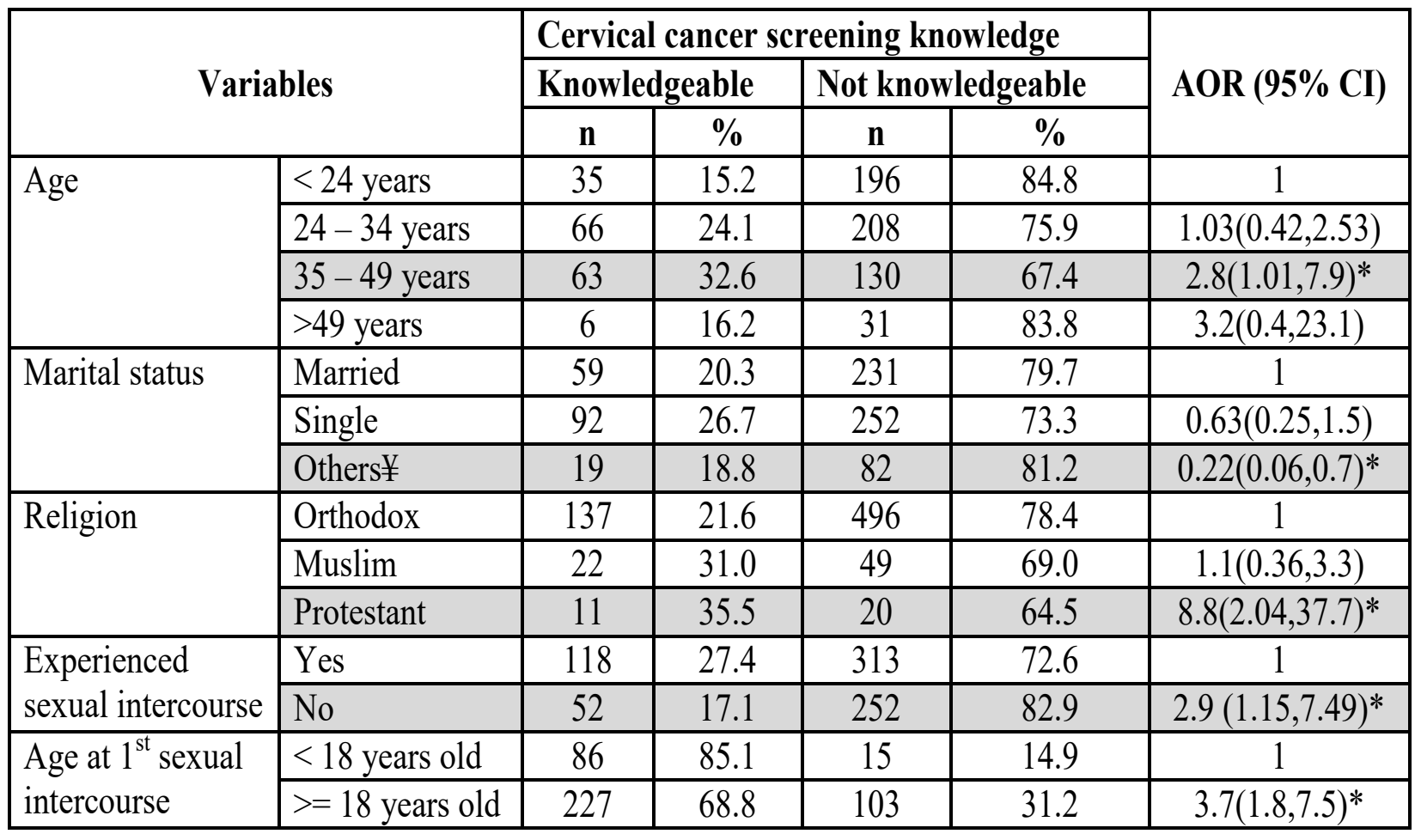

Others $¥=$ Divorced $\&$ Widowed, AOR $=$ Adjusted Odds Ratio, $*=$ P Value $<0.05$

Factors associated with attitude towards cervical cancer

Candidate predictor variables from bivariate regression with attitude of cervical cancer were entered to the multivariable logistic regression analysis. Logistic regression analysis showed that age (AOR $=1.9,95 \% \mathrm{CI}: 1.3,3.0$ \& $\mathrm{AOR}=2.0,95 \%$ CI: $1.2,3.5)$, educational status (AOR $=1.8,95 \%$ CI: $1.0,3.3, \mathrm{AOR}=2.9,95 \% \mathrm{CI}: 1.5,5.3)$, AOR $=1.9,95 \%$ CI: $1.04,3.3 \&$ AOR $=2.2,95 \%$ CI: $1.12,4.4)$ and use of contraceptives $(\mathrm{AOR}=0.6,95 \%$
CI: $0.5,09)$ were found to be significantly associated with attitude towards cancer of the cervix. Study participants who were found in the age range of 24-49 years were almost 2 times more likely to have a positive attitude when compared with other age groups. Regarding educational status, those who had BSc Degree and above were 2.2 times more likely to have a positive attitude when compared with illiterate counterparts. Those who did not use contraceptives were 0.6 less likely to have a positive attitude when compared with those who used contraceptives (Table 6). 
Table 6: Factors associated with attitude on cervical cancer screening, Finoteselam City Administration, Amhara Region, Northwest Ethiopia, 2017.

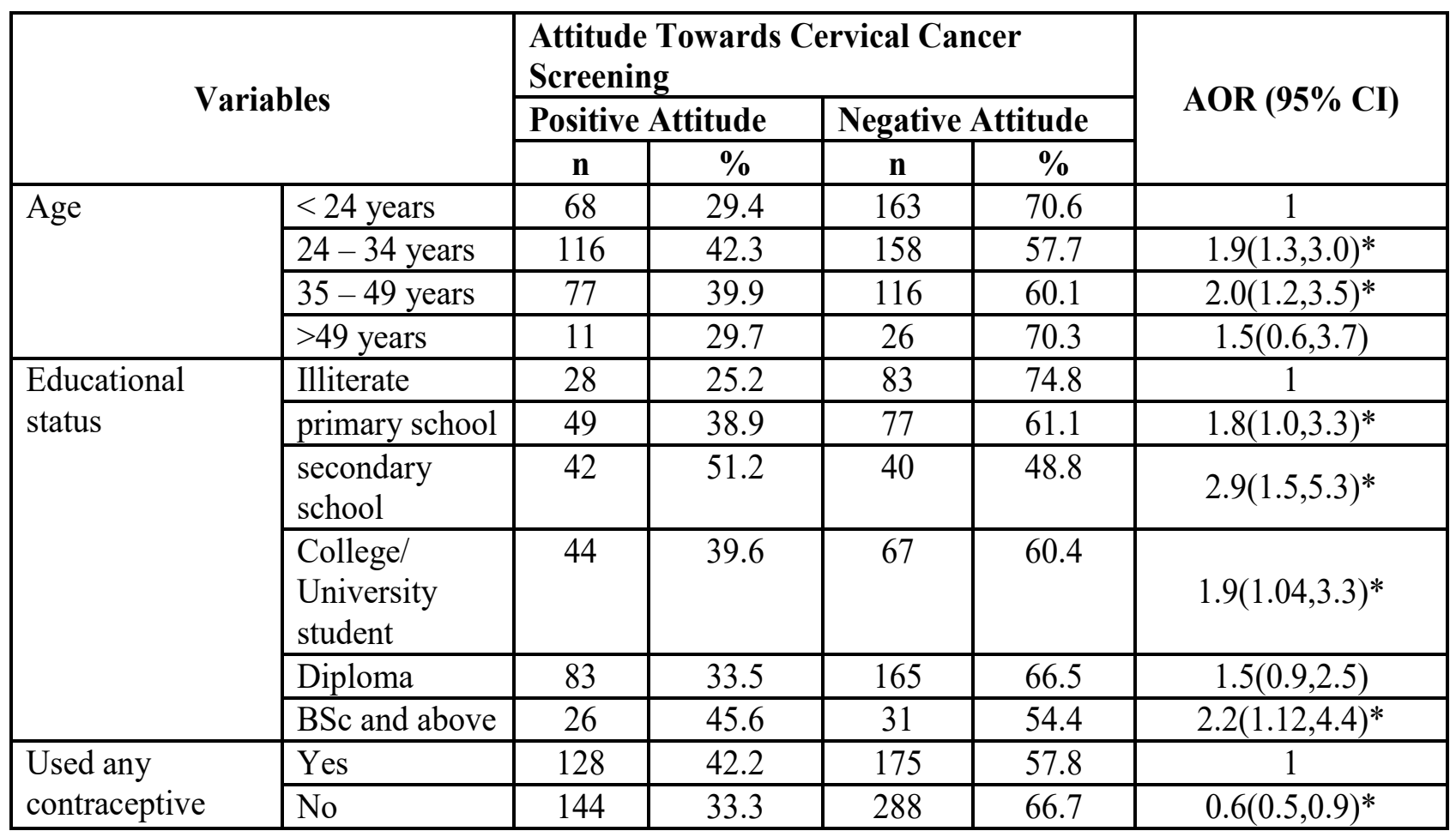

AOR $=$ Adjusted Odds Ratio, $*=\mathrm{P}$ Value $<0.05$

\section{Discussion}

Despite the high growing burden of cervical cancer, it continues to receive low public health priority in Africa, largely because of limited resources and other pressing public health problems, including communicable diseases such as acquired immune deficiency syndrome (AIDS), malaria, and tuberculosis. It may also be in part due to a lack of awareness about the magnitude of the current and future cancer burden among policy makers, the general public, and international private or public health agencies ${ }^{7}$.

The aim of this study was to assess knowledge, attitude and practice towards cervical cancer for women residing at Finote selam City Administration.

In the current study, the overall knowledge of the reproductive age women towards cervical cancer was $23.1 \%$, $63 \%$ having a negative attitude towards cervical cancer screening and $7.3 \%$ had a history of screening for the disease.

A study done in Addis Ababa on reproductive age women showed that the overall knowledge of cervical cancer and attitude towards cervical cancer screening was $43.8 \%$ \& $56 \%$ respectively and an overall practice of cervical cancer screening was $3.5 \%{ }^{15}$. Another study which was done at the Southern Ethiopia, Hossana Town, also showed that $53.7 \%$ of participants had good knowledge, $34.8 \%$ had negative attitude and $9.9 \%$ of study participants had been screened for the cervical cancer ${ }^{16}$. The probable discrepancy here maybe, because of the study setting difference where Addis Ababa and Hossana Town are urban cities whereas Finote selam is relatively a rural town. These and other factors may have their own impact on the information access, lifestyle differences, and service utilization access differences. All factors have their own 
role on study participants having the varied knowledge, attitudes and screening practice for the disease.

In a study done in Malaysia, the prevalence of ever having had a Pap test was 6\%. Majority of the participants had adequate knowledge about risk factors for cervical cancer. The highest knowledge about cervical cancer risk factor reported by the respondents was having more than one sex partner, whereas the lowest was the relationship between HPV and cervical cancer ${ }^{17}$.

In a study done in Tanzania district less than one quarter $(22.6 \%)$ of the participants had obtained cervical cancer screening $^{18}$. Even if the Tanzania's study was conducted on rural reproductive age women, there may be a presumed difference with our study because in Tanzania, there is screening service access, awareness creation activities regarding the disease and screening availability was highly promoted in the area. Whereas in our setting all awareness creation about the disease is almost null and this makes the initiation to participate in the screening service very low.

In a study done in Quatar, almost $40 \%$ had had a Pap smear test at least once and $85.5 \%$ of the rest would have a test if they were told that the procedure was painless and simple. Over half wanted the test to be done in the well-woman clinic at the primary health care center ${ }^{19}$. The possible discrepancy here may be lifestyle changes, active involvement of health professionals in awareness creation.

In a study done in India, $85 \%$ of the HCPs were aware of the major risk factors and symptoms of cancer cervix. Eighteen point four percent of the female HCPs had ever undergone cervical cancer screening ${ }^{3}$. Another study from Northern Ethiopia, Gondar, showed that from 633 women only $31 \%$ were knowledgeable about the disease ${ }^{1}$. The difference in these results may be attributed to the fact that Gondar is relatively a large town, having a teaching hospital and many more private clinics that may have their own role to create awareness towards the disease. Even there is an oncology center in Gondar.

In the current study, age of the study participants, marital status, religion, and experiencing sexual intercourse were found to affect knowledge of cervical cancer. This finding is somewhat not consistently with a study done in Ni- geria, which revealed that educational level was found to significantly affect knowledge of cervical cancer screening test. Age and marital status were not found to affect knowledge of cervical cancer ${ }^{2}$. This discrepancy may be due to that differences in socio-cultural and economic variations in the regions of Ethiopia and that of Nigeria. Whereas our finding is somewhat consistent with a study done in Malaysia that revealed that age, marital status, ethnicity, and monthly family income were significantly associated with knowledge of cervical cancer screening ${ }^{17}$.

\section{Conclusion}

The mean age of participants was 30.82.7 \pm 9.83SD years, with a minimum of 17 and maximum of 88 years. Averagely from those who practiced sexual intercourse, the average age was 19.18 years and 10 years was the minimum one.

Almost one-fourth of the study participants experienced sexual intercourse below the age of 18 years.

Five hundred nine $(69.3 \%)$ had heard about the disease (cervical cancer). Three hundred eighty-six (75.8\%) of study participants did not know that cervical cancer can be cured in its earliest stage.

Four hundred sixty-three $(63 \%)$ had a negative attitude for cervical cancer screening and only fifty-four participants participated in cervical cancer screening. From those who were not screened for the disease, 334 (45.4\%) thought they were healthy, thus didnot need the screening. It will be beneficial to work with religious leaders on awareness creation program towards cervical cancer programs.

Ministry of health in collaboration with other concerned bodies should design a strategy to educate the women and public about cervical cancer including information on risk factors, signs and symptoms of the disease and availability of screening.

Establishing population-based cervical smear screening programs for cervical cancer shouldbe done because such programs have shown the effectiveness of screening in reducing the mortality rate.

\section{Competing interests}

The authors declare that they have no competing interests. 


\section{Authors' contributions}

AS wrote the proposal, participated in data collection, analyzed the data and drafted the paper. TD \& WA approved the proposal with some revisions, participated in data analysis and manuscript preparation. All authors read and approved the final manuscript.

\section{Acknowledgements}

We are very grateful to Bahir Dar University College of Medicine \& Health Sciences Institutional Review Board for the approval of the ethical clearance and for their technical support of this study. West Gojjam Health Desk for the provision of a letter of approval to conduct the study in Finote selam City Administration. Then, we would like to thank all women who participated in this study for their commitment in responding to our interviews.

\section{References}

1. Getahun F, Mazengia F, Abuhay M, Birhanu Z. Comprehensive knowledge about cervical cancer is low among women in NorthWest Ethiopia. BMC Cancer [Internet]. 2013;13(2):1-7. Available from: http://www.biomedcentral.com/1471-2407/13/2\%250

2. Eke NO, Ezeama C, Eke CO, Eleje GU, Akabuike JC, Iu E. Knowledge of Cervical Cancer and its Screening Amongst Female Workers In Nnewi, Nigeria. Afri medic J. 2010; 2010;1(1):1-6. PubMed

3. Anantharaman V V. A cross-sectional study on knowledge, attitude, and practice on cervical cancer and screening among female health care providers of Chennai corporation , 2013. J Acad Med Sci. 2013;2(4):124-8. PubMed.

4. Raychaudhuri S, Mandal S. MINI-REVIEW Current Status of Knowledge, Attitude and Practice ( KAP ) and Screening for Cervical Cancer in Countries at Different Levels of Development. Asian Pacific J Cancer Prev. 2012;13:4221-7.

5. Adamu AN, Abiola AO, Ibrahim MTO. The effect of health education on the knowledge, attitude, and uptake of free Pap smear among female teachers in Birnin Kebbi , North Western Nigeria. Niger J Clin Pract. 2012;15(3). 6. Mccarey C, Pirek D, Tebeu PM, Boulvain M, Doh AS, Petignat P. Awareness of HPV and cervical cancer pre- vention among Cameroonian healthcare workers. $B M C$ Womens Health [Internet]. 2011;11(45):1-7. Available from: http://www.biomedcentral.com/1472-6874/11/45

7. American Cancer Society. Cancer in Africa. 2011.

8. Emanuel GO, Adesola BO, Oluwole KA, Mathew AS, Toyin EO, Aishatu O. Awareness and Practice of Cervical Cancer Screening among Women Accessing Care in a Rural Tertiary Hospital in Nigeria. Clin Med Res. 2015;4(4):120 PubMed -6.

9. Association. EC. Cancer in Ethiopia [Internet]. 2015. Available from: http://www.yeeca.org/Cancer in Ethiopia.htm

10. Tesfa A. Combating Cervical Cancer in Ethiopia Addressing the Screening and Treatment Gap : The Single-Visit Approach. 2010.

11. Mutyaba T, Mmiro FA, Weiderpass E. Knowledge, attitudes and practices on cervical cancer screening among the medical workers of Mulago Hospital, Uganda. BMC Med Educ. 2006;4:4 - PubMed ;7.

12. Report E, Morris BS, Comments N. CCC Welcomes $26 \mathrm{New}$ "See and Treat" Trainees in Addis Ababa, Ethiopia! [Internet]. 2016. 1-21 p. Available from: http:// www.curecervicalcancer.org/category/ethiopia-blog/ Accessed

13. Terefe Y GA, Terefe Y, Gaym A. Knowledge, attitude and practice of screening for carcinoma of the cervix among reproductive health clients at three teaching hospitals, Ethiopian Journal of Reproductive Health, May 2008, Volume 2, Number 1 Addis Ababa, Ethiopia. Ethiop J Reprod Heal. 2008;2(1):8.

14. John John J. The knowledge, attitude, practice and perceived barriers towards screening for premalignant cervical lesions among women age 18years and above, in songea urban, ruvuma,Muhimbili University of Health and Allied Sciences, 2011, Tanzania 31. Muhimbili University; 2011.

15. Getachew E, Addisse A, Getachew S, Submitted T, Science H, Health P, et al. Knowledge Attitude and Practice on Cervical Cancer and Screening among Reproductive health Service Clients, Addis Ababa, Ethiopia. Addis Ababa University; 2015.

16. Aweke YH, Ayanto SY, Ersado TL. Knowledge, attitude and practice for cervical cancer prevention and 
control among women of childbearing age in Hossana Town, Hadiya zone, Southern Ethiopia: Community-based cross-sectional study. PLoS One. 2017 Jul 25; 12(7):e0181415. doi: 10.1371/journal.pone.0181415. eCollection 2017.

17. Al-naggar RA, Low WY, Isa Z. Knowledge and barriers towards cervical cancer screening among young women in Malaysia. Asian Pacific J Cancer Prev. 2010;11:867-73. 18. Lyimo FS, Beran TN. Demographic, knowledge, atti- tudinal, and accessibility factors associated with uptake of cervical cancer screening among women in a rural district of Tanzania : Three public policy implications. BMCPublic Health [nternet]. 2012;12(1):22. Available from: http:// www.biomedcentral.com/1471-2458/12/22

19. Aseel MT. Knowledge, attitude and practices regarding cervical cancer and screening among women visiting primary health care in Qatar. East Mediterr Heal J. 2011;17(11). 